\title{
Association and interaction between model for end-stage liver disease score and minimally invasive treatment with regard to mortality of patients with hepatitis B virus-associated hepatocellular carcinoma and portal vein tumor thrombi
}

\author{
MENGGE LI $^{1 *}$, YALIN ZHAO ${ }^{2 *}$, XIAOLI LIU ${ }^{1 *}$, ZHIBO DANG $^{1}$, \\ XINHUI WANG ${ }^{1}$, YUYONG JIANG ${ }^{1,3}$ and ZHIYUN YANG ${ }^{1,3}$ \\ ${ }^{1}$ Department of Traditional Chinese Medicine, Beijing Ditan Hospital, Capital Medical University, \\ Beijing 100015; ${ }^{2}$ Digestive Department, The People's Hospital of Hebi, Hebi, Henan 458000; \\ ${ }^{3}$ Collabrorative Innovation Center of Infectious Diseases, Capital Medical University, Beijing 100015, P.R. China
}

Received January 23, 2018; Accepted August 8, 2018

DOI: $10.3892 / \mathrm{ol} .2018 .9590$

\begin{abstract}
The development of minimally invasive treatment over the last two decades has had a great impact on hepatitis $\mathrm{B}$ virus (HBV)-associated primary liver cancer. The model for end-stage liver disease (MELD) score is the optimal evaluated parameter for mortality in patients with end-stage liver disease. However, the association between MELD score and minimally invasive treatment with regard to the mortality of patients with HBV-associated hepatocellular carcinoma (HCC) with a portal vein tumor thrombus (PVTT) remains unclear. In the present study, a total of 173 patients who had been diagnosed with HBV-associated HCC and PVTT in the Beijing Ditan Hospital (Beijing, China), between January 2012 and January 2015, were screened. Follow-up was performed to observe the survival time and collect information on the demographic characteristics and associated clinical indicators present in the cohort. The patient's age, sex, laboratory parameters and the use of minimally invasive treatment were analyzed with SPSS 20.0 software. Independent risk factors for mortality were screened by Cox regression analysis. Logistic regression indicated that there was an interaction between the MELD score and minimally invasive treatment. In addition, a MELD score $\leq 17.85$ was associated with a lower mortality rate subsequent to minimally invasive treatment.
\end{abstract}

Correspondence to: Dr Zhiyun Yang, Department of Traditional Chinese Medicine, Beijing Ditan Hospital, Capital Medical University, 8 Jingshun East Street, Chaoyang, Beijing 100015, P.R. China E-mail: yangzhiyun2016@163.com

${ }^{*}$ Contributed equally

Key words: hepatitis B virus-associated hepatocellular carcinoma, portal vein tumor thrombus, prediction model, interaction

\section{Introduction}

Primary liver cancer is the fifth most common malignancy and the second leading cause of cancer-associated mortality worldwide (1). Hepatocellular carcinoma (HCC) accounts for $>80 \%$ of primary liver cancer cases (2). Patients with chronic hepatitis B virus (CHB) have been reported to frequently progress to cirrhosis and liver failure (3). Furthermore, it has been demonstrated that $\mathrm{CHB}$ is associated with the development of HCC. It has been estimated that CHB-associated HCC accounts for $>80 \%$ of $\mathrm{HCC}$ cases in areas with high hepatitis $\mathrm{B}$ virus (HBV) incidence (4). HCC is prone to invade the intrahepatic vessels, particularly the portal vein system (4). It has been reported that portal vein tumor thrombus (PVTT) occurs frequently in patients with HCC (5). Patients with HCC and PVTT often present with portal vein hypertension, ascites, tumor dissemination and deterioration of liver function. In addition, poor prognosis and a survive rate of 2-3 months has been reported for these patients when no treatment is received (6). Since radical resection cannot be performed in patients with HCC and PVTT, minimally invasive treatment is widely used for treating patients with HCC and PVTT $(7,8)$. The development of minimally invasive treatments in the past 20 years has greatly improved (9). It has been reported that the most widely used minimally invasive treatments include transarterial chemoembolization (TACE) and radiofrequency ablation (RFA) (10). It has been reported that TACE is the optimal treatment recommended by the European Association for the study of the liver and by the American Association for the study of liver diseases in the HCC management guidelines for patients with intermediate HCC (11). According to the guidelines for the management of HCC, RFA is one of the first-line treatments for patients with Barcelona clinic liver cancer (BCLC)-0 which is in the earliest stages of cancer, and BCLC-A grade (12).

Liver function is one of the important factors that affect tumor prognosis. The model for end-stage liver disease score (MELD), which includes serum creatinine, bilirubin and the 
international normalized prothrombin time ratio, serves as an alternative non-invasive biomarker of liver function (13). In the present study, the associations between liver function and minimally invasive treatment and the survival rate of patients with liver cancer were determined. However, the association between MELD score and minimally invasive treatment requires further investigation. The purpose of the present study was to analyze the demographic characteristics, laboratory indicators and imaging data in patients with HBV-associated HCC and PVTT, and to further examine the effect of MELD score and minimally invasive treatment on the 1-year overall survival rate of the aforementioned patients.

\section{Materials and methods}

Patients. A total 173 patients (18 to 80 years old, the median age was 56 years) with $\mathrm{HBV}$-associated primary liver cancer and PVTT were included in the present retrospective study. Samples $(n=173)$ were collected from Beijing Ditan Hospital (Beijing, China) between January 2012 and January 2015. The present study was approved by the Ethics Committee of the Beijing Ditan Hospital, Capital Medical University, in accordance with the Declaration of Helsinki (approval no. 7142081). Written informed consent was obtained from all individual participants included in the present study.

Inclusion criteria. Patients with hepatitis B surface antigen-positive primary liver cancer were included in the present study. The pathological diagnostic criteria for primary liver cancer were as follows: Tissue specimens were diagnosed as primary liver cancer by histopathology and cytology, and tissue specimens were acquired from liver lesions or extrahepatic metastases by biopsy or surgical resection. Clinical diagnostic criteria for primary liver cancer were in accordance with the 'primary liver cancer diagnosis and treatment norms' (14). PVTT was diagnosed on the basis of a filling defect in the portal vein or its branch on contrast-enhanced computed tomography or magnetic resonance imaging.

Exclusion criteria. Patients with the following characteristics were excluded from the present study: i) Hepatitis C, human immunodeficiency virus infection, autoimmune liver disease, genetic metabolic liver disease, drug-induced liver disease and other chronic liver diseases; ii) diseases affecting the heart, lungs, kidneys, brain, blood and other vital organs; iii) severe mental illness; iv) pregnancy and lactation; v) metastatic liver cancer; vi) treatment with radiotherapy or chemotherapy; and vii) incomplete clinical data.

Statistical analysis. Statistical analysis was performed using SPSS 20.0 software (IBM Corp., Armonk, NY, USA). Mean \pm standard deviation was used to fit the normal distribution. Student's t-test was used to compare continuous variables and the significant differences between two groups (15). In non-normal distribution data, the two groups were compared using the Wilcoxon rank sum test. Frequency represented the count data, which were compared with the $\chi^{2}$ test. In univariate analyses, the $\chi^{2}$ test or Fisher exact test were utilized to compare categorical data and the two sample groups (16). Logistic regression analysis was used for multivariate analysis and interaction between MELD and minimally invasive treatment. In multivariate regression analysis, single factor $(\mathrm{P}<0.05)$ was used to calculate the independent risk factors. $\mathrm{P}<0.05$ was considered to indicate a statistically significant difference. Overall survival rates were calculated by the Kaplan-Meier method with the log-rank test applied for comparison. Bonferroni's test was used to correct for the multiple comparisons. Kaplan-Meier survival curves were drawn using GraphPad 5.0 software (GraphPad Software, Inc., La Jolla, CA, USA).

\section{Results}

Patients and disease characteristics. Patients and disease characteristics are summarized in Table I. The present study included 173 patients with $\mathrm{HBV}$-associated $\mathrm{HCC}$ who received PVTT treatment in the Beijing Ditan Hospital between January 2012 and January 2015 (Fig. 1). Complete follow-up of the patients ( $n=173)$ was available until the time of patient mortality or for the following 2 years. Out of the 173 patients participating in the present study, a total of 121 succumbed within a year and 52 survived. The survival rate was $42.98 \%$ and the median survival time was 5 months. Baseline characteristics were compared between the survival group and the mortality group. The alanine transaminase, aspartate transaminase, direct bilirubin, glutamyl transferase, alkaline phosphatase and MELD scores were significantly higher in the mortality group $(\mathrm{P}<0.05)$, while the cholinesterase and percentage of cluster of differentiation (CD) $4^{+} / \mathrm{CD}^{+} \mathrm{T}$ cells were significantly lower in the mortality group relative to the survival group $(\mathrm{P}<0.05)$. In addition, there was an increased number of patients with $\alpha$-fetoprotein (AFP) $>1,000 \mathrm{ng} / \mathrm{ml}, \mathrm{HBV}$-DNA >500 copies and abdominal effusion in the mortality group compared with that in the survival group $(\mathrm{P}<0.001$, Table I).

Site of tumor thrombus invasion is associated with mortality rate. The association was analyzed between the site of invasion of the tumor thrombus and patient mortality. As indicated in Table II, the highest mortality rate $(54.5 \%)$ was exhibited in patients where the tumor thrombus had invaded the trunk and the branches of the portal vein, whereas the lowest mortality rate $(7.4 \%)$ was indicated in patients where the tumor thrombus had only invaded the trunk. Kaplan-Meier survival curves illustrated the survival time of patients with tumor thrombus invasion on a 1-year mortality scale. The tumor thrombus invasion site significantly affected the survival time of patients with HBV-associated HCC ( $\mathrm{P}=0.003$; Fig. 2). The patients with a tumor thrombus invasion site only in the trunk of the portal vein experienced a longer survival time ( $\mathrm{P}=0.003$; Fig. 2).

Association between minimally invasive treatment and mortality. The effect of minimally invasive treatment for a cancer embolus on patient mortality rate was analyzed. The mortality rates of conservative treatment and minimally invasive treatment were 75.95 and $64.89 \%$, respectively, indicating a significant difference $(\mathrm{P}<0.01)$ between the two types of treatment. By comparing different minimally invasive treatment methods, the lowest mortality rate of $52.3 \%$ was indicated in patients with the combination treatment of TACE and RFA (Table III). The mortality rate was $75.9 \%$ in patients without minimally invasive treatment. 
Table I. Baseline characteristics of the study cohort.

\begin{tabular}{|c|c|c|c|}
\hline Variables & Survival group $(n=52)$ & Mortality group $(n=121)$ & P-value \\
\hline Age, years & $53.560 \pm 1.960$ & $54.780 \pm 1.479$ & 0.859 \\
\hline \multicolumn{4}{|l|}{ Sex, n (\%) } \\
\hline Male & $42(29.000)$ & $103(79.000)$ & 0.503 \\
\hline Female & 10 & 18 & \\
\hline Alcohol consumption, $\mathrm{n}$ & 19 & 52 & 0.410 \\
\hline WBC, $\times 10^{9} / 1$ & $4.500(2.000,7.000)$ & $5.000(3.500,7.000)$ & 0.100 \\
\hline $\mathrm{HGB}, \mathrm{g} / 1$ & $109.00 \pm 7.499$ & $119.332 \pm 3.745$ & 0.900 \\
\hline PLT, $x 10^{9} / 1$ & $118.75 \pm 17.009$ & $122.457 \pm 9.356$ & 0.440 \\
\hline NLR & $3.150(2.278,5.237)$ & $3.404(2.293,4.986)$ & 0.210 \\
\hline ALT, U/l & $35.500(15.500,51.750)$ & $45.000(32.000,62.000)$ & $0.004^{\mathrm{a}}$ \\
\hline $\mathrm{AST}, \mathrm{U} / \mathrm{l}$ & $40.000(23.750,51.750)$ & $85.000(50.000,168.000)$ & $<0.001^{\mathrm{a}}$ \\
\hline $\mathrm{DBIL}, \mu \mathrm{mol} / 1$ & $8.000(5.000,13.500)$ & $11.00(7.000,25.000)$ & $0.010^{\mathrm{a}}$ \\
\hline GGT, U/1 & $107.000(58.000,235.250)$ & $148.000(95.500,271.500)$ & $<0.001^{\mathrm{a}}$ \\
\hline ALP, U/1 & $134.188 \pm 12.234$ & $167.530 \pm 11.367$ & $<0.001^{\mathrm{a}}$ \\
\hline CHE, U/1 & $4426.938 \pm 606.710$ & $3855.385 \pm 224.471$ & $0.039^{\mathrm{a}}$ \\
\hline ALB, g/l & $33.000(29.250,37.750)$ & $34.000(30.000,40.500)$ & 0.687 \\
\hline $\mathrm{Cr}, \mu \mathrm{mol} / \mathrm{l}$ & $69.500(52.250,76.500)$ & $63.000(55.000,73.000)$ & 0.284 \\
\hline PTA, $\%$ & $70.000(57.750,76.750)$ & $75.000(66.000,81.500)$ & 0.650 \\
\hline $\mathrm{CD}^{+} / \mathrm{CD}^{+}, \%$ & $2.500(2.000,3.000)$ & $2.000(1.000,2.000)$ & $0.007^{\mathrm{a}}$ \\
\hline $\operatorname{AFP}(>1,000 \mathrm{ng} / \mathrm{ml}), \mathrm{n}(\%)$ & $9(12.676)$ & $62(87.324)$ & $<0.001^{\mathrm{a}}$ \\
\hline HBV DNA (>500 copies/l), n (\%) & $9(14.754)$ & $52(85.246)$ & $<0.001^{\mathrm{a}}$ \\
\hline Treatment method, n (\%) & & & $0.010^{\mathrm{a}}$ \\
\hline Minimally invasive & $33(63.462)$ & $61(50.413)$ & \\
\hline Conservative & $19(36.538)$ & $60(49.587)$ & \\
\hline \multicolumn{4}{|l|}{ MELD score, n (\%) } \\
\hline$\leq 17.85$ & $30(37.975)$ & $49(62.025)$ & $0.037^{\mathrm{a}}$ \\
\hline$>17.85$ & $22(23.404)$ & $72(76.595)$ & \\
\hline \multicolumn{4}{|l|}{ Complication, n (\%) } \\
\hline Abdominal effusion & $27(23.894)$ & $86(76.106)$ & $0.030^{\mathrm{a}}$ \\
\hline Abdominal infection & $12(22.222)$ & $42(77.778)$ & 0.150 \\
\hline
\end{tabular}

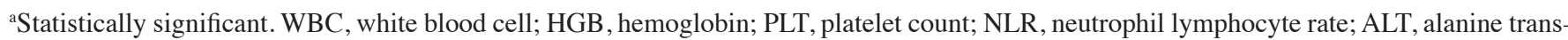
aminase; AST, aspartate transaminase; DBIL, direct bilirubin; GGT, glutamyl transferase; ALP, alkaline phosphatase; CHE, cholinesterase; ALB, albumin; Cr, creatinine; PTA, prothrombin activity; HBV, hepatitis B virus; CD, cluster of differentiation; AFP, $\alpha$-fetoprotein; MELD, model for end-stage liver disease. Student's t-test was used to compare normal distribution data. In non-normal distribution data, the two groups were compared using the Wilcoxon rank sum test (Mann-Whitney U test). Frequency represented the count data, which were analysed by the $\chi^{2}$ test (Pearson $\chi^{2}$ test). Normal distribution is represented by mean \pm standard deviation and non-normal distribution is represented by median (upper quartile and lower quartile).

A Kaplan-Meier curve for 1-year mortality was used to compare the survival times among patients with conservative treatment and patients with different types of minimally invasive treatment. Results indicated that the patients with minimally invasive treatment exhibited a significantly longer survival time compared with patients with conservative treatment ( $\mathrm{P}=0.007$; Fig. 3A). Furthermore, the minimally invasive treatments were further divided into the TACE, RFA, combined TACE and RFA, and conservative treatment groups. It was indicated that the minimally invasive treatment of TACE plus RFA exerted the best survival time of patients with HBV-associated HCC in all group $(\mathrm{P}=0.005$; Fig. 3B).
Multivariate analysis. The Kaplan-Meier curve for 1-year mortality was used to compare the survival time between patients with AFP $>1,000 \mathrm{ng} / \mathrm{ml}$ and AFP $\leq 1,000 \mathrm{ng} / \mathrm{ml}$, and between patients with HBV-DNA $>500$ copies/l and HBV-DNA $\leq 500$ copies/1. As indicated in Fig. 4A, in patients with AFP $\leq 1,000 \mathrm{ng} / \mathrm{ml}$ refer to a significantly higher survival rate compared with patients with AFP $>1,000 \mathrm{ng} / \mathrm{ml}(\mathrm{P}<0.001)$. In addition, patients with HBV-DNA $\leq 500$ copies/1 refer to a significantly higher survival rate compared with patients with HBV-DNA >500 copies/1 ( $\mathrm{P}=0.001)$ (Fig. 4B).

Using multivariate logistic regression analyses (Table IV), the independent risk factors of mortality of $\mathrm{HBV}$-associated HCC with PVTT were HBV-DNA >500 copies/1, $(\mathrm{P}=0.013$; 
Table II. Baseline distribution of tumor thrombus.

\begin{tabular}{lccc}
\hline Location & $\begin{array}{c}\text { Survival } \\
\text { group }(\mathrm{n}=52)\end{array}$ & $\begin{array}{c}\text { Mortality } \\
\text { group }(\mathrm{n}=121)\end{array}$ & P-value \\
\hline Trunk + branch, n (\%) & $19(36.538)$ & $66(54.545)$ & $0.001^{\mathrm{a}}$ \\
Branch, n (\%) & $20(38.462)$ & $46(38.017)$ & \\
Trunk, n (\%) & $13(25.000)$ & $9(7.438)$ & \\
\hline
\end{tabular}

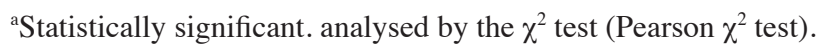

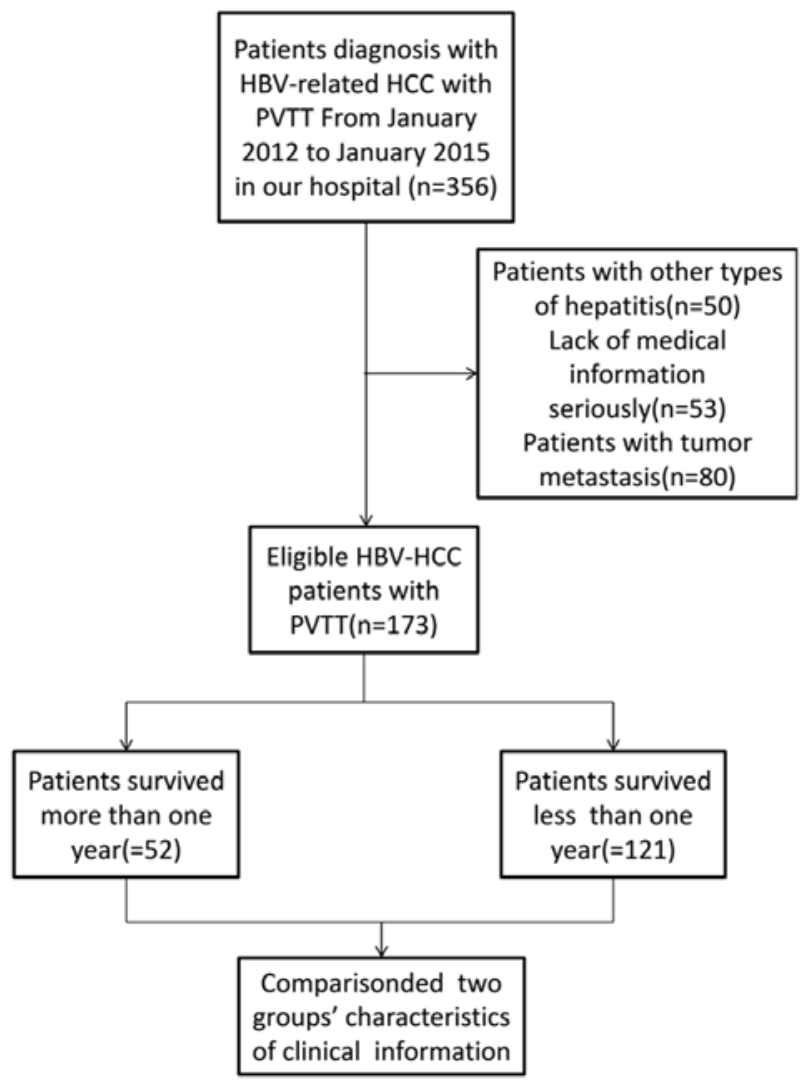

Figure 1. Flow chart of the included patients. HCC, hepatocellular carcinoma; PVTT, portal vein tumor thrombus; HBV, hepatitis B virus.

odds ratio, 4.582) and $\mathrm{AFP}>1,000 \mathrm{ng} / \mathrm{ml}(\mathrm{P}=0.012$; odds ratio, 2.167). Furthermore, the interaction between MELD score and minimally invasive treatment was indicated $(\mathrm{P}=0.021$; odds ratio, 2.167; 95\% confidence interval, 1.124-4.177) in Table IV.

In order to verify the interaction between the treatment and the MELD score, the mean survival times of patients with minimally invasive treatments or conservative therapy were analyzed when the MELD score was different (Table V). The cut-off value of the MELD score (17.85) was obtained by using Jorden index. The present study also indicated the survival curves of different types of treatment for different MELD scores (Fig. 5A and B). The results indicated that patients with minimally invasive treatment had a longer survival time compared with patients with conservative treatment (Table V). The patients in the minimally invasive treatment group with a MELD score $\leq 17.85$, experienced a significantly longer survival time compared with that of patients with a MELD
Table III. Minimally invasive treatment of baseline distribution.

\begin{tabular}{lccc}
\hline Treatment & $\begin{array}{c}\text { Survival } \\
\text { group }(\mathrm{n}=52)\end{array}$ & $\begin{array}{c}\text { Mortality } \\
\text { group }(\mathrm{n}=121)\end{array}$ & P-value \\
\hline TACE + RFA, n (\%) & $21(40.385)$ & $23(19.008)$ & $0.016^{\mathrm{a}}$ \\
TACE, n (\%) & $12(23.077$ & $33(27.273)$ & \\
RFA, n (\%) & $0(0.000)$ & $5(4.132)$ & \\
None, n (\%) & $19(36.538)$ & $60(51.240)$ & \\
\hline
\end{tabular}

aStatistically significant. TACE, transarterial chemoembolization; RFA, radiofrequency ablation. Analysed by the $\chi^{2}$ test (Pearson $\chi^{2}$ test).

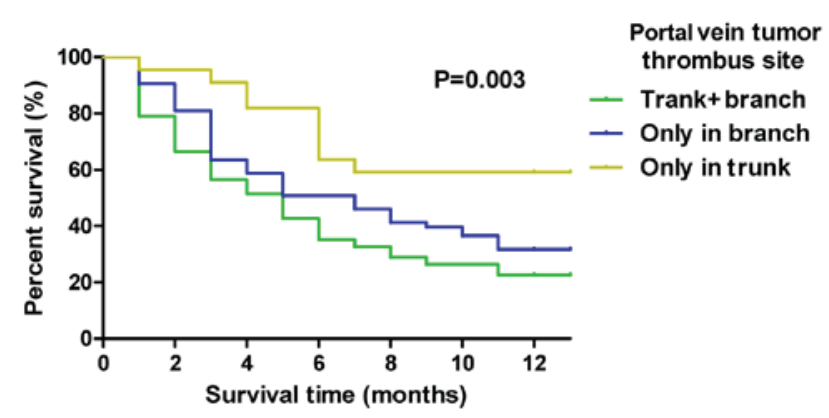

Figure 2. Site of invasion of the tumor thrombus was associated with overall survival rate. Kaplan-Meier curve compared the probability of survival between the portal vein sites of invasion, namely the trunk and branches, of the tumor thrombus.

score $>17.85$ (Table V; Fig. 5A and B). In addition, the survival time of patients receiving different types of minimally invasive treatments, in addition to having different MELD scores, was analyzed (Table VI). Results indicated that the patients with a MELD score $\leq 17.85$ experienced a significantly longer survival time for all types of minimally invasive treatments.

\section{Discussion}

Liver cancer is prone to metastasis and confers a poor prognosis (17). Portal vein invasion is common in HCC with intrahepatic metastasis, and is one of the leading causes for tumor recurrence and tumor-associated mortality subsequent to surgery (16). A retrospective study of 601 patients indicated that PVTT significantly affected the survival rate of patients independently (18). However, there have been few studies on prognostic models of HCC with PVVT. The purpose of the present study was to identify independent risk factors for HBV-associated HCC and to establish a predictive model. It was indicated that minimally invasive treatment is the optimal treatment choice for patients with HCC and PVTT plus a low MELD score in comparison to patients with a high MELD score (threshold value, 17.85).

Previous studies have demonstrated the effect of PVTT on patient prognosis. It was reported that patients with HBV-associated HCC and PVTT experienced a low median survival time of 2-4 months $(19,20)$. A recent study conducted by Kokudo et al (21) indicated that the median survival time of patients in the liver resection group was 1.77 years longer than 
Table IV. Logistic regression analysis of significant variables.

\begin{tabular}{lccr}
\hline Variables & B & OR & 95\% CI \\
\hline HBV DNA, copies/l & & Reference & \\
$\leq 500$ & & 4.582 & $1.377-15.242$ \\
$>500$ & 1.522 & & 0.013 \\
AFP, ng/ml & & Reference & \\
$\leq 1,000$ & 1.598 & 4.945 & $1.420-17.223$ \\
$>1,000$ & & Reference & 0.012 \\
MELD score* minimally invasive treatment & 0.773 & 2.167 & $1.124-4.177$ \\
\end{tabular}

HBV, hepatitis B virus; AFP, $\alpha$-fetoprotein; CI, confidence interval; MELD, model for end-stage liver disease; OR, odds ratio*; interacted with . Logistic regression analysis.

Table V. Survival time (months) of patients with minimally invasive and conservative treatment and different MELD scores.

\begin{tabular}{lccc}
\hline MELD score & Minimally invasive & Conservative & P-value \\
\hline$\leq 17.85$ & $8.652 \pm 0.645$ & $6.273 \pm 0.863$ & 0.012 \\
$>17.85$ & $6.714 \pm 0.565$ & $4.739 \pm 0.690$ & \\
\hline
\end{tabular}

MELD, model for end-stage liver disease. Analysed by the $\chi^{2}$ test (Pearson $\chi^{2}$ test).

that of patients in the non-liver resection group and 0.88 years longer than that of patients in the non-liver resection group in a propensity score-matched cohort. In addition, a survival benefit of chemoembolization plus iodine-125 seed implantation has been reported in unresectable HBV-associated HCC with PVTT $(22,23)$. In the present study, it was indicated that the median survival time was 5 months in patients with HBV-associated HCC and PVTT. The median survival time was significantly longer compared with results reported in previous studies $(19,20)$, suggesting that improvements in treatment methods may have increased patient survival time. In the present study, AFP levels were significantly associated with a poor prognosis in patients with HCC. Since AFP levels have been reported to reflect tumor progression, this marker is frequently measured during patient treatment (24). In previous studies, AFP response had been reported as a predictive factor for radiological response, recurrence and survival in early and advanced HCC cases (25-28). Consistent with previous studies, the present study indicated that AFP $>1,000 \mathrm{ng} / \mathrm{ml}$ was one of the independent risk factors for survival time of patients with HBV-associated HCC and PVTT. The copies of HBV-DNA represent viral load, which are risk factors for the development of cirrhosis and HCC. The copies of HBV-DNA have also been indicated to be associated with a poor prognosis in patients with HCC $(29,30)$. The present study demonstrated that patients with HBV-DNA >500 copies/1 experienced a shorter survival time compared with patients with HBV-DNA $\leq 500$ copies/l. The aforementioned result was consistent with previous studies $(20,30)$.
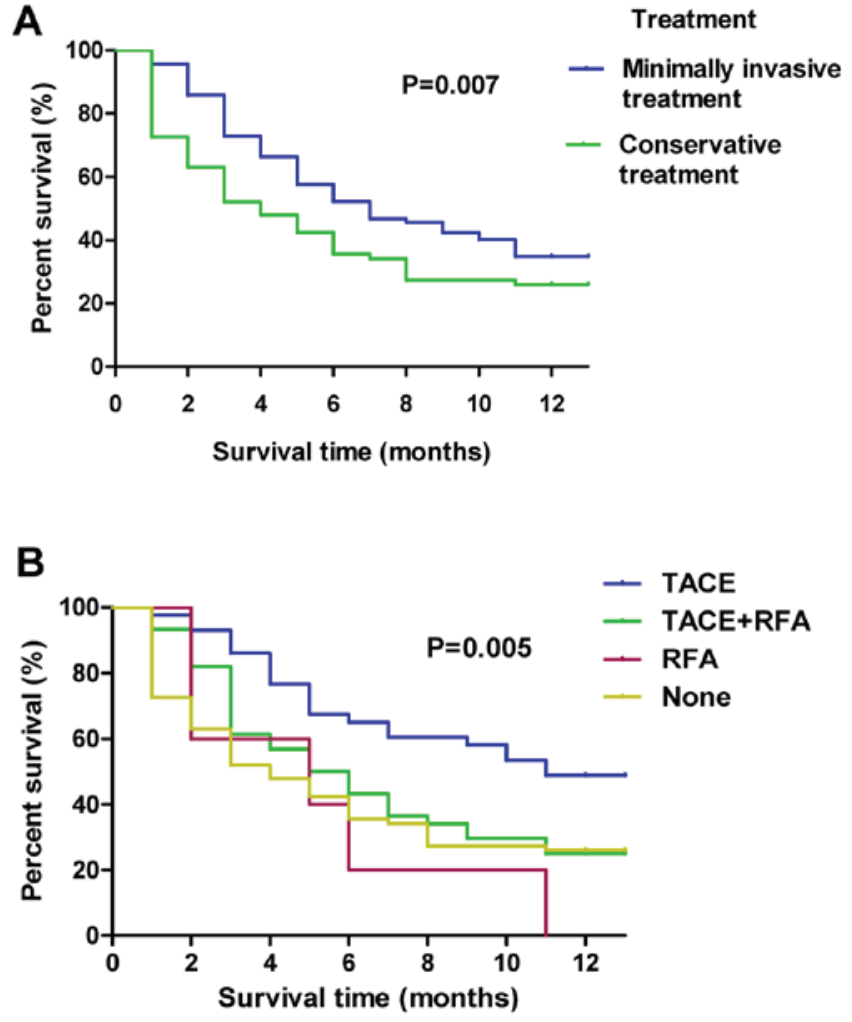

Figure 3. A comparison of overall survival rate following minimally invasive or conservative treatment. (A) A comparison of the survival probability between the minimally invasive and conservative treatment groups. (B) A comparison of the survival probability among the different minimally invasive treatments, including TACE and RFA. TACE, transarterial chemoembolization; RFA, radiofrequency ablation.

Hirooka et al (31) indicated that the cumulative survival rates at 6, 12 and 24 months were 100, 89.7 and $78.8 \%$, respectively, with the combined treatment of TACE and RFA and that the median survival time was 953 days. For patients treated only with TACE, the cumulative survival rates at 6 , 12 and 24 months were 84.9, 56.1 and $16.9 \%$, respectively, and the median survival time was 352 days. In the present study, it was demonstrated that the combination of TACE and RFA significantly increased the survival time in patients with HCC. 
Table VI. Survival time (months) of patients with different minimally invasive treatments and different MELD scores.

\begin{tabular}{lccc}
\hline Treatment & $\begin{array}{c}\text { MELD score } \\
\leq 17.85\end{array}$ & $\begin{array}{c}\text { MELD score } \\
>17.85\end{array}$ & P-value \\
\hline TACE + RFA & $9.680 \pm 0.815$ & $8.000 \pm 1.094$ & 0.008 \\
TACE & $7.667 \pm 1.051$ & $5.977 \pm 0.817$ & \\
RFA & $6.000 \pm 2.646$ & $4.000 \pm 2.000$ & \\
None & $6.273 \pm 0.863$ & $4.739 \pm 0.690$ & \\
\hline
\end{tabular}

MELD, model for end-stage liver disease; TACE, transarterial chemoembolization; RFA, radiofrequency ablation. Analysed by the $\chi^{2}$ test (Pearson $\chi^{2}$ test).

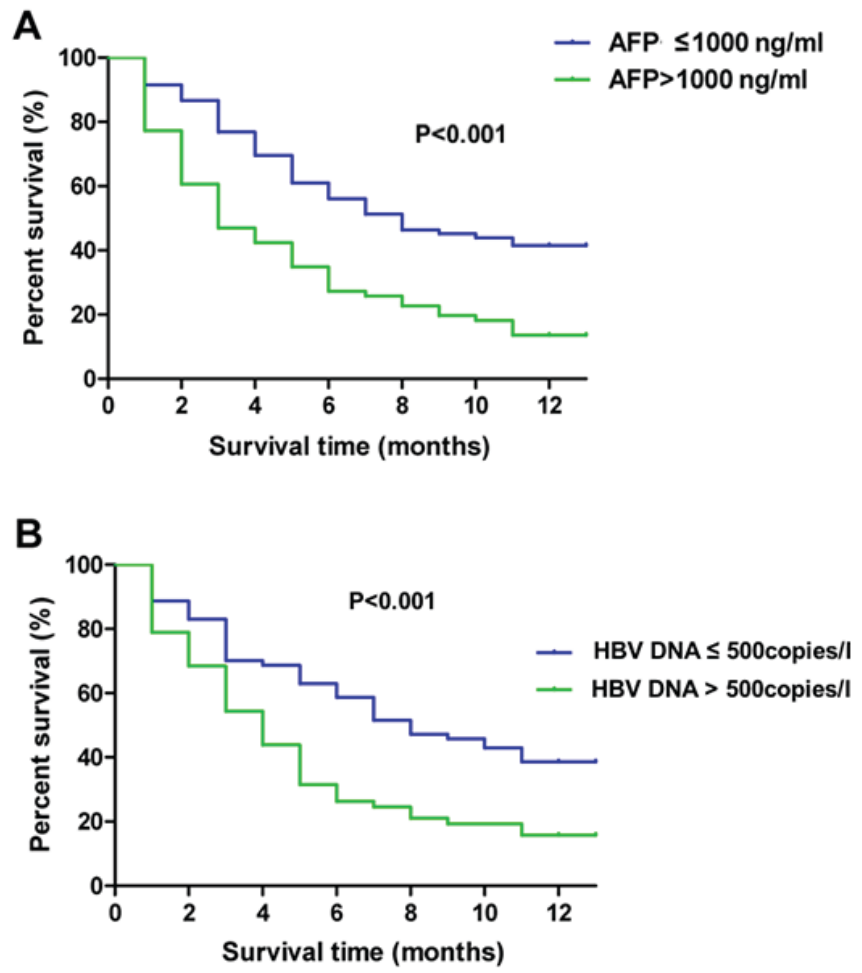

Figure 4. Associations among AFP, HBV DNA and overall survival. (A) A comparison of the survival probability between patients with AFP $\leq 1,000 \mathrm{ng} / \mathrm{ml}$ and AFP $>1,000 \mathrm{ng} / \mathrm{ml}$. (B) A comparison of the survival probability between patients with HBV DNA $\leq 500$ copies/l and HBV DNA $>500$ copies/l. AFP, $\alpha$-fetoprotein; HBV, hepatitis B virus.

The MELD scoring system has been widely used to assess the prognosis of liver function and liver-associated diseases (13). The cut-off value of the MELD score (17.85) was obtained by using Jorden index (https://www.scalelive. com/youden-index.html). The results of the present study indicated that a MELD score $\leq 17.85$ in patients with HCC and PVTT displayed a better prognosis compared with a MELD score $>17.85$. Furthermore, patient prognosis became worse as MELD score increased. The aforementioned result was consistent with previous studies $(32,33)$. In addition, the present study also indicated an interaction between MELD score and minimally invasive treatment, suggesting that minimally invasive treatment may improve the prognosis in patients with a MELD
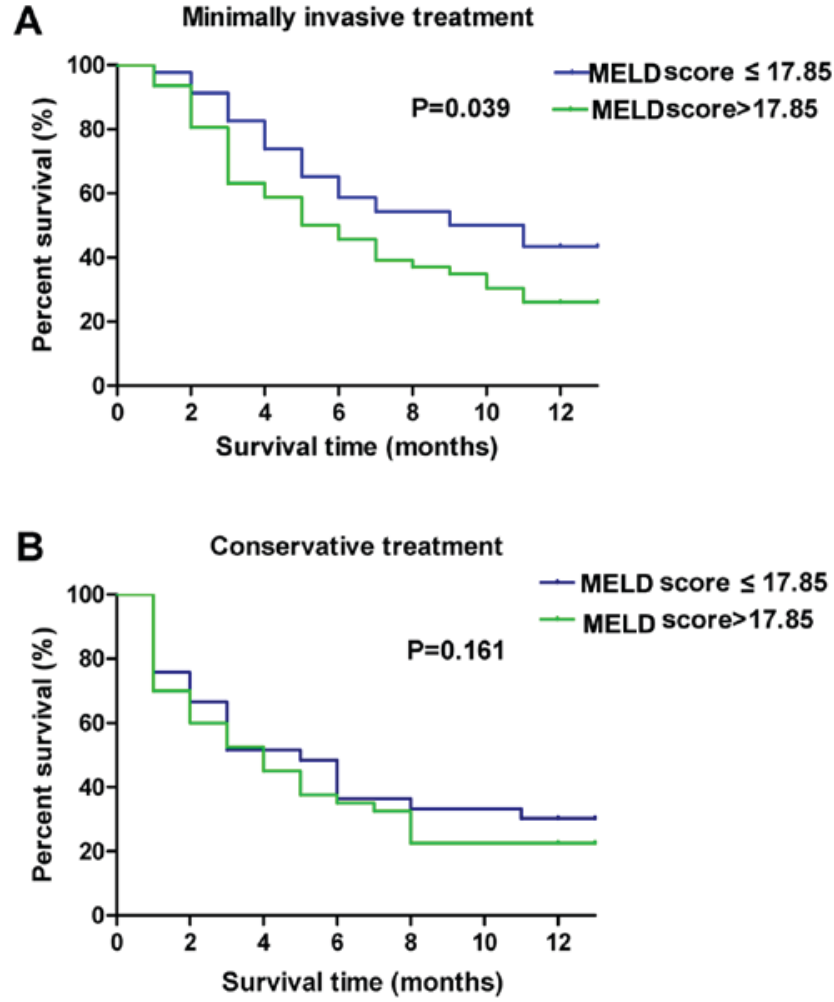

Figure 5. Survival curves of minimally invasive and conservative treatments for different MELD grades. Kaplan-Meier method compared the probability of survival between patients with a MELD score $\leq 17.85$ and a MELD score $>17.85$ in minimally invasive and conservative treatment groups. MELD, model for end-stage liver disease.

score $\leq 17.85$. However, minimally invasive treatment did not improve the prognosis in patients with a meld score $>17.85$.

In conclusion, the present study provided a theoretical basis for the treatment of patients with HCC and PVTT. However, the number of samples in the present study was limited and therefore, further investigation is required to expand the sample size, verifying the present study results.

\section{Acknowledgements}

We would like to thank Dr. Lingling He from Beijing Ditan Hospital, Capital Medical University (Beijing, China) and Dr. Shuan Zhang from the Digestive department, Chinese Medicine Hospital of Zhengzhou (Zhengzhou, China) for assistance with the follow-up information.

\section{Funding}

The present study was funded by the Capital Health Research and Development of Special (grant no. 2016-2-2171; Beijing, China), the Science and Technology Project of Beijing Municipal Education Commission (grant no. SQKM201610025026; Beijing, China) and the Beijing Municipal Science and Technology Commission (grant no. Z171100001017082; Beijing, China).

\section{Availability of data and materials}

The datasets used or analyzed during the current study are available from the corresponding author on reasonable request. 


\section{Authors' contributions}

ZYY and XLL designed the study; YLZ, XLL and MGL collected and analyzed the data; MGL and XLL wrote the manuscript; XLL acquired, analysed and interpreted the data; XHW and ZBD provided patients' data; YYJ, XLL and ZYY were responsible for the interpretation of data and revision. ZYY and XLL approved the final version.

\section{Ethics approval and consent to participate}

The study was approved by the ethics committee of Beijing Ditan Hospital, Capital Medical University. Written informed consent was obtained from each patient.

\section{Patient consent for publication}

Written informed consent was obtained from each patient. Information that could identify individual participants during or after data collection was not accessible.

\section{Competing interests}

The authors declare that they have no competing interests.

\section{References}

1. Taketomi A: Clinical trials of antiangiogenic therapy for hepatocellular carcinoma. Int J Clin Oncol 21: 213-218, 2016.

2. Torre LA, Bray F, Siegel RL, Ferlay J, Lortet-Tieulent J and Jemal A: Global cancer statistics, 2012. CA Cancer J Clin 65 87-108, 2015.

3. Facciorusso A, Di Maso M and Muscatiello N: Drug-eluting beads versus conventional chemoembolization for the treatment of unresectable hepatocellular carcinoma: A meta-analysis. Dig Liver Dis 48: 571-577, 2016.

4. Zhang ZM, Lai EC, Zhang C, Yu HW, Liu Z, Wan BJ, Liu LM, Tian ZH, Deng H, Sun QH and Chen XP: The strategies for treating primary hepatocellular carcinoma with portal vein tumor thrombus. Int J Surg 20: 8-16, 2015.

5. Bucci L, Garuti F, Lenzi B, Pecorelli A, Farinati F, Giannini EG, Granito A, Ciccarese F, Rapaccini GL, Di Marco M, et al: The evolutionary scenario of hepatocellular carcinoma in Italy: An update. Liver Int 37: 259-270, 2017.

6. Ramirez AG, Munoz E, Holden AE, Adeigbe RT and Suarez L: Incidence of hepatocellular carcinoma in Texas Latinos, 1995-2010: An update. PLoS One 9: e99365, 2014.

7. Nakazawa T, Adachi S, Kitano M, Isobe Y, Kokubu S, Hidaka H, Ono K, Okuwaki Y, Watanabe M, Shibuya A, et al: Potential prognostic benefits of radiotherapy as an initial treatment for patients with unresectable advanced hepatocellular carcinoma with invasion to intrahepatic large vessels. Oncology 73: 90-97, 2017.

8. Tanaka Y, Nakazawa T, Komori S, Hidaka H, Okuwaki Y, Takada J, Watanabe M, Shibuya A, Minamino T, Yamamoto $\mathrm{H}$, et al: Radiotherapy for patients with unresectable advanced hepatocellular carcinoma with invasion to intrahepatic large vessels: Efficacy and outcomes. J Gastroenterol Hepatol 29: 352-357, 2014.

9. Stippel DL, Wahba R, Bruns CJ, Bunck A, Baues C and Persigehl T: Image-guided, minimally invasive surgery and other local therapeutic procedures for primary liver tumors. Chirug, 2018 (In German).

10. Bruix J and Sherman M; American Association for the Study of Liver Diseases: Management of hepatocellular carcinoma: An update. Hepatology 53: 1020-1022, 2011.

11. Shen A, Tang C, Wang Y, Chen Y, Yan X, Zhang C, Liu R, Wei X, Zhu Y, Zhang $\mathrm{H}$ and Wu Z: A systematic review of sorafenib in Child-Pugh A patients with unresectable hepatocellular carcinoma. J Clin Gastroenterol 47: 871-880, 2013.
12. Cheah YL and Chow PKH: Liver transplantation for hepatocellular carcinoma: An appraisal of current controversies. Liver Cancer 1: 183-189, 2012

13. Malinchoc M, Kamath PS, Gordon FD, Peine CJ, Rank J and ter Borg PC: A model to predict poor survival in patients undergoing transjugular intrahepatic portosystemic shunts. Hepatology 31 : 864-871, 2000

14. Eguchi S, Kanematsu T, Arii S, Omata M, Kudo M, Sakamoto M, Takayasu K, Makuuchi M, Matsuyama Y and Monden M; Liver Cancer Study Group of Japan: Recurrence-free survival more than 10 years after liver resection for hepatocellular carcinoma. Br J Surg 98: 552-557, 2011

15. Zou Z, Yuan Z, Zhang Q, Long Z, Chen J, Tang Z, Zhu Y, Chen S, Xu J, Yan M, et al: Aurora kinase A inhibition-induced autophagy triggers drug resistance in breast cancer cells. Autophagy 8: 1798-1810, 2012.

16. Gao J, Zou Z, Gao J, Zhang H, Lin Z, Zhang Y, Luo X, Liu C, Xie J and Cai C: Increased expression of HMGB3: A novel independent prognostic marker of worse outcome in patients with esophageal squamous cell carcinoma. Int J Clin Exp Pathol 8: $345-352,2015$.

17. Tandon P and Garcia-Tsao G: Prognostic indicators in hepatocellular carcinoma: A systematic review of 72 studies. Liver Int 29: 502-510, 2009.

18. Zhang TT, Zhao XQ, Liu Z, Mao ZY and Bai L: Factors affecting the recurrence and survival of hepatocellular carcinoma after hepatectomy: A retrospective study of 601 Chinese patients. Clin Transl Oncol 18: 831-840, 2016.

19. Schöniger-Hekele M, Müller C, Kutilek M, Oesterreicher C, Ferenci P and Gangl A: Hepatocellular carcinoma in Central Europe: Prognostic features and survival. Gut 48: 103-109, 2001.

20. Llovet JM, Bustamante J, Castells A, Vilana R, Ayuso Mdel C, Sala M, Brú C, Rodés J and Bruix J: Natural history of untreated nonsurgical hepatocellular carcinoma: Rationale for the design and evaluation of therapeutic trials. Hepatology 29: 62-67, 1999.

21. Kokudo T, Hasegawa K, Matsuyama Y, Takayama T, Izumi N, Kadoya M, Kudo M, Ku Y, Sakamoto M, Nakashima O, et al: Survival benefit of liver resection for hepatocellular carcinoma associated with portal vein invasion. J Hepatol 65: 938-943, 2016.

22. Huang M, Lin Q, Wang H, Chen J, Bai M, Wang L, Zhu K, Jiang Z, Guan S, Li Z, et al: Survival benefit of chemoembolization plus Iodine125 seed implantation in unresectable hepatitis B-related hepatocellular carcinoma with PVTT: A retrospective matched cohort study. Eur Radiol 26: 3428-3436, 2016.

23. Lu XJ, Dong J, Ji LJ, Luo JH, Cao HM, Xiao LX, Zhou J and Ling CQ: Safety and efficacy of TACE and gamma knife on hepatocellular carcinoma with portal vein invasion. Gut 65: 715-716, 2016.

24. Riaz A, Ryu RK, Kulik LM, Mulcahy MF, Lewandowski RJ, Minocha J, Ibrahim SM, Sato KT, Baker T, Miller FH, et al: Alpha-fetoprotein response after locoregional therapy for hepatocellular carcinoma: Oncologic marker of radiologic response, progression, and survival. J Clin Oncol 27: 5734-5742, 2009.

25. Chan SL, Mo FK, Johnson PJ, Hui EP, Ma BB, Ho WM, Lam KC, Chan AT, Mok TS and Yeo W: New utility of an old marker: Serial alpha-fetoprotein measurement in predicting radiologic response and survival of patients with hepatocellular carcinoma undergoing systemic chemotherapy. J Clin Oncol 27: 446-452, 2009.

26. Lee MH, Kim SU, Kim DY, Ahn SH, Choi EH, Lee KH, Lee DY, Seong J, Han KH, Chon CY and Park JY: Early on-treatment predictions of clinical outcomes using alpha-fetoprotein and des-gamma-carboxy prothrombin responses in patients with advanced hepatocellular carcinoma. J Gastroenterol Hepatol 27: 313-322, 2012

27. Nobuoka D, Kato Y, Gotohda N, Takahashi S, Nakagohri T, Konishi M, Kinoshita T and Nakatsura T: Postoperative serum alpha-fetoprotein level is a useful predictor of recurrence after hepatectomy for hepatocellular carcinoma. Oncol Rep 24: 521-528, 2010.

28. Bujold A, Massey CA, Kim JJ, Brierley J, Cho C, Wong RK, Dinniwell RE, Kassam Z, Ringash J, Cummings B, et al: Sequential phase I and II trials of stereotactic body radiotherapy for locally advanced hepatocellular carcinoma. J Clin Oncol 31: 1631-1639, 2013. 
29. Kubo S, Hirohashi K, Tanaka H, Tsukamoto T, Shuto T, Yamamoto T, Ikebe T, Wakasa K, Nishiguchi S and Kinoshita H: Effect of viral status on recurrence after liver resection for patients with hepatitis B virus-related hepatocellular carcinoma. Cancer-Am Cancer Soc 88: 1016-1024, 2000.

30. Ohkubo K, Kato Y, Ichikawa T, Kajiya Y, Takeda Y, Higashi S, Hamasaki K, Nakao K, Nakata K and Eguchi K: Viral load is a significant prognostic factor for hepatitis B virus-associated hepatocellular carcinoma. Cancer 94: 2663-2668, 2002.

31. Hirooka M, Koizumi Y, Kisaka Y, Abe M, Murakami H, Matsuura B, Hiasa Y and Onji M: Mass reduction by radiofrequency ablation before hepatic arterial infusion chemotherapy improved prognosis for patients with huge hepatocellular carcinoma and portal vein thrombus. AJR Am J Roentgenol 194: W221-W226, 2010.
32. Lai JC, Covinsky KE, Dodge JL, Boscardin WJ, Segev DL, Roberts JP and Feng S: Development of a novel frailty index to predict mortality in patients with end-stage liver disease. Hepatology 66: 564-574, 2017.

33. Benko T, Gallinat A, Minor T, Saner FH, Sotiropoulos GC, Paul A and Hoyer DP: The postoperative model for end stage liver disease score as a predictor of short-term outcome after transplantation of extended criteria donor livers. Eur J Gastroenterol Hepatol 29: 716-722, 2017.

This work is licensed under a Creative Commons Attribution-NonCommercial-NoDerivatives 4.0 International (CC BY-NC-ND 4.0) License. 